\title{
Perspective Piece \\ Chloroquine and Hydroxychloroquine for the Prevention or Treatment of COVID-19 in Africa: Caution for Inappropriate Off-label Use in Healthcare Settings
}

\begin{abstract}
Pascale M. Abena, ${ }^{1}$ Eric H. Decloedt, ${ }^{2}$ Emmanuel Bottieau, ${ }^{3}$ Fatima Suleman, ${ }^{4}$ Prisca Adejumo, ${ }^{5}$ Nadia A. Sam-Agudu, ${ }^{6,7,8}$ Jean-Jacques Muyembe TamFum, ${ }^{9}$ Moussa Seydi, ${ }^{10}$ Serge P. Eholie, ${ }^{11,12}$ Edward J. Mills, ${ }^{13}$ Oscar Kallay, ${ }^{14}$ Alimuddin Zumla, ${ }^{15,16}$ and Jean B. Nachega ${ }^{17,18,19 *}$

${ }^{1}$ Infectious Diseases Outpatient Clinic, Cameroon and Infectious Diseases Society of Cameroon, Yaoundé, Douala, Cameroon; ${ }^{2}$ Division of Clinical Pharmacology, Department of Medicine, Stellenbosch University, Cape Town, South Africa; ${ }^{3}$ Department of Clinical Sciences, Institute of Tropical Medicine, Antwerp, Belgium; ${ }^{4}$ Discipline of Pharmaceutical Sciences, University of Kwazulu-Natal, Durban, South Africa; ${ }^{5}$ Department of Nursing, University of Ibadan, Ibadan, Nigeria; ' Institute of Human Virology and Department of Pediatrics, University of Maryland School of Medicine, Baltimore, Maryland; ${ }^{7}$ International Research Center of Excellence, Institute of Human Virology Nigeria, Abuja, Nigeria; ${ }^{8}$ Department of Paediatrics, University of Cape Coast School of Medical Sciences, Cape Coast, Ghana; ${ }^{9}$ Department of Medical Microbiology and Virology, National Institute of Biomedical Research (INRB), Faculty of Medicine, University of Kinshasa, Kinshasa, Democratic Republic of the Congo; ${ }^{10}$ Service de Maladies Infectieuses et Tropicales, Centre Hospitalo-Universitaire de Fann, Université Cheik Anta-Diop, Dakar, Sénégal; ${ }^{11}$ Unit of Infectious Diseases, Treichville University Teaching Hospital, Abidjan, Côte d'Ivoire; ${ }^{12}$ Unité de Dermatologie et Infectiologie, Unité de Formation et de Recherche, Université Félix Houphouet Boigny, Abidjan, Côte d'Ivoire; ${ }^{13}$ University of Kigali School of Public Health, Kigali, Rwanda; ${ }^{14}$ Erasme Hospital, Free University of Brussels, Brussels, Belgium; ${ }^{15}$ Department of Infection, Division of Infection and Immunity, Centre for Clinical Microbiology, University College London, London, United Kingdom ${ }^{16}$ National Institute for Health Research Biomedical Research Centre, University College London Hospitals, London, United Kingdom ${ }^{17}$ Center for Infectious Diseases, at Stellenbosch University, Cape Town, South Africa; ${ }^{18}$ Department of International Health and Epidemiology, Johns Hopkins Bloomberg School of Public Health, Baltimore, Maryland; ${ }^{19}$ University of Pittsburgh
\end{abstract} Graduate School of Public Health and Center for Global Health, Pittsburgh, Pennsylvania

\begin{abstract}
The novel severe acute respiratory syndrome-coronavirus-2 pandemic has spread to Africa, where nearly all countries have reported laboratory-confirmed cases of novel coronavirus disease (COVID-19). Although there are ongoing clinical trials of repurposed and investigational antiviral and immune-based therapies, there are as yet no scientifically proven, clinically effective pharmacological treatments for COVID-19. Among the repurposed drugs, the commonly used antimalarials chloroquine (CQ) and hydroxychloroquine (HCQ) have become the focus of global scientific, media, and political attention despite a lack of randomized clinical trials supporting their efficacy. Chloroquine has been used worldwide for about 75 years and is listed by the WHO as an essential medicine to treat malaria. Hydroxychloroquine is mainly used as a therapy for autoimmune diseases. However, the efficacy and safety of CQ/HCQ for the treatment of COVID-19 remains to be defined. Indiscriminate promotion and widespread use of CQ/HCQ have led to extensive shortages, self-treatment, and fatal overdoses. Shortages and increased market prices leave all countries vulnerable to substandard and falsified medical products, and safety issues are especially concerning for Africa because of its healthcare system limitations. Much needed in Africa is a cross-continental collaborative network for coordinated production, distribution, and post-marketing surveillance aligned to low-cost distribution of any approved COVID-19 drug; this would ideally be piggybacked on existing global aid efforts. Meanwhile, African countries should strongly consider implementing prescription monitoring schemes to ensure that any off-label CQ/HCQ use is appropriate and beneficial during this pandemic.
\end{abstract}

\section{PERSPECTIVE}

Novel coronavirus disease (COVID-19), caused by the novel severe acute respiratory syndrome-coronavirus-2 (SARSCoV-2), has rapidly spread into a global pandemic. Africa initially appeared spared, but as of this writing, all countries except Lesotho have confirmed cases. As of April 15, 2020, there were 11,367 confirmed COVID-19 cases, with 523 deaths (4.6\% case fatality) reported across the WHO African region. ${ }^{1}$ In other settings such as the United States, Europe, and China, morbidity and mortality have been highest in those older than 60 years and with underlying comorbidities such as arterial hypertension, heart disease, diabetes, and chronic lung disease; young adults and children seem to have relatively mild disease and low mortality. ${ }^{2,3}$

To date, there are no proven, clinically effective pharmacological treatments against COVID-19, but multiple ongoing

\footnotetext{
${ }^{*}$ Address correspondence to Jean B. Nachega, Infectious Diseases and Microbiology, Department of Epidemiology and Center for Global Health, University of Pittsburgh Graduate School of Public Health, 130 DeSoto St., Pittsburgh, PA, 15261. E-mail: jbn16@pitt.edu
}

trials are evaluating novel and repurposed drugs. ${ }^{4}$ Among the repurposed drugs being rapidly investigated are the commonly used antimalarial and anti-inflammatory drugs chloroquine (CQ) and hydroxychloroquine (HCQ). ${ }^{5}$ These drugs have become the focus of global scientific, media, and political attention despite the lack of randomized controlled trials supporting their efficacy against COVID-19. ${ }^{6}$ Chloroquine has been used worldwide for about 75 years, and it is listed by the WHO as an essential medicine for malaria, whereas HCQ is widely used to treat autoimmune diseases such as systemic lupus erythematosus (SLE) and rheumatoid arthritis (RA). ${ }^{7}$ Both drugs have an established clinical safety profile, ${ }^{8}$ but their efficacy and safety for COVID-19 treatment or prevention remain to be defined. ${ }^{9,10}$

Chloroquine is a 4-aminoquinoline that was synthesized in Germany by Bayer in 1934 and emerged in the 1940s as an effective substitute for quinine, an antimalarial therapy used for centuries. ${ }^{11}$ Once a frontline drug for the treatment and prophylaxis of malaria, the efficacy of $\mathrm{CQ}$ was mostly lost because of the emergence of CQ-resistant Plasmodium falciparum strains in all endemic regions, including sub-Saharan 
Africa. Since about 2005, CQ has been replaced by artemisininbased combination therapy to treat uncomplicated $P$. falciparum malaria across Africa, but it is still widely used to treat nonfalciparum malaria, primarily outside of Africa. ${ }^{12}$ After $C Q$ was found to have persistent immunomodulatory effects after cessation of short-term treatment, Winthrop developed and patented HCQ, which has an N-hydroxyl-ethyl side chain in place of the $\mathrm{N}$-diethyl group, and therefore less tissue accumulation and a more favorable safety profile than $\mathrm{CQ} .{ }^{13,14}$

There are rational arguments, preclinical evidence of activity, and long-term evidence of safety for other indications to justify $\mathrm{CQ} / \mathrm{HCQ}$ trials for the treatment and prevention of COVID-19. ${ }^{15}$ Their mechanisms of action are incompletely understood but may include fusion and uncoating blockade, ${ }^{17}$ Iysosomal alkalinization, ${ }^{18}$ interaction with the angiotensin-2 converting enzyme receptor, ${ }^{19}$ and immune modulation. ${ }^{20}$ However, in vitro antiviral activity of CQ/HCQ has not yet been translated into efficacy for any viral infection, and these drugs have been detrimental in some studies (e.g., for the treatment of chikungunya). ${ }^{16}$ Of note, for SARS-CoV-2, the in vitro activity of $\mathrm{HCQ}$ appears to be greater than that of $C Q$, which might allow for a lower dosage for HCQ. ${ }^{21,22}$ To date, the quality of available evidence for the clinical effectiveness of CQ/HCQ alone or in combination with other drugs (e.g., azithromycin) is low, because of small sample size, poorly defined clinical outcomes, and lack of randomization in published studies. ${ }^{23-26}$ Thus, the results of early clinical studies cannot yet be considered conclusive.

There remains an urgent need for high-quality evidence on the clinical value of $\mathrm{CQ} / \mathrm{HCQ}$ alone or in combination with other drugs for the treatment of COVID-19. One global-scale effort is the ongoing WHO Solidarity trial, a large, adaptive, five-arm multinational (including South Africa) trial comparing four potential COVID-19 regimens: remdesivir, $\mathrm{HCQ}$, lopinavir-ritonavir, and lopinavir-ritonavir plus interferon beta, all of which are compared with optimal supportive care, with in-hospital mortality as the primary end point. Secondary end points will be the duration of hospital stay and proportion of patients requiring intensive care unit admission or mechanical ventilation. The adaptive study design allows for dropping poorly performing arms and including additional promising therapeutics. $^{27}$ Discovery is a component of the Solidarity trial, with identical arms and more complex end points, and is funded by the "Institut National de la Santé et de la Recherche Médicale," France's national health and medical research agency. More than 500 patients have already been enrolled in the Discovery trial, and preliminary analysis is ongoing. Also, the Recovery trial (for randomized evaluation) is a UK component of Solidarity, with more than 1,500 participants already enrolled. ${ }^{27}$ Also, CQ/HCQ Prevention of COVID-19 in the
Healthcare Setting (COPCOV), a large $(n=40,000)$ multicentric trial in which participants will be randomized to receive either CQ or HCQ versus placebo, is being launched in Europe and Asia, and participation of African sites is being considered. $^{28}$

Unfortunately, indiscriminate promotion of $\mathrm{CQ} / \mathrm{HCQ}$ (with or without azithromycin) based on the aforementioned low-quality data for COVID-19 treatment has led to widespread shortages, self-use, and fatal overdoses. ${ }^{29}$ Chloroquine (and to a lesser extent $\mathrm{HCQ}$ ) has been used for decades with few major safety issues at the usual antimalarial dosages in short-course regimens ( $2.5 \mathrm{~g}$ in 3 days for $\geq 60 \mathrm{~kg}$ adults). ${ }^{30}$ Although rare, cardiac toxicity (corrected QT interval [QTc] prolongation leading to torsades de pointes and ventricular fibrillation) is a serious, lifethreatening complication, especially in patients with underlying cardiac disease, concurrent use of other drugs with QTc effect, or with supratherapeutic dosing. ${ }^{26}$ The therapeutic window is however larger with HCQ, which is mainly used in chronic administration for rheumatic disorders, usually at dosages of 200 to $400 \mathrm{mg} /$ day in adults. The major toxicity of chronic CQ/HCQ use is retinopathy. ${ }^{31}$ Other important adverse effects associated with $\mathrm{CQ} / \mathrm{HCQ}$ are listed in Table $1 .{ }^{31-36}$ Of great concern are frequent drug-drug interactions between $\mathrm{CQ} / \mathrm{HCQ}$ and other medications used for prevalent chronic diseases in Africa, such as HIV infection and tuberculosis, and the concurrent use of antibiotics such as fluoroquinolones (Table 2). ${ }^{37-44}$ As an example, coadministration of azithromycin with $\mathrm{CQ} / \mathrm{HCQ}$ should be cautiously approached and closely monitored because of additive risk for QTc prolongation and subsequent cardiac complications. $^{32}$

Of note, $P$. falciparum resistance to $C Q$ is widespread in sub-Saharan Africa, and artemisinin-based combination therapy has been the first-line treatment for uncomplicated malaria in all African countries for more than 10 years. ${ }^{11} \mathrm{Al}-$ though currently inappropriate, widespread CQ/HCQ use for COVID-19 treatment or prevention should therefore have little impact on $P$. falciparum treatment outcomes. However, this may increase selection of resistance to $\mathrm{CQ}$ in $P$. falciparum, which has decreased in recent years, or in other Plasmodium species, for which $C Q$ remains the treatment of choice. ${ }^{45}$ Furthermore, we call for caution regarding the widespread use of azithromycin (coadministered with $\mathrm{CQ} / \mathrm{HCQ}$ ) for treatment of COVID-19, as it may increase selection of bacterial resistance to this macrolide. In sub-Saharan Africa, azithromycin is an important treatment for bacterial infections including typhoid fever, especially where multidrug resistance (ampicillin, chloramphenicol, trimethoprim-sulfamethoxazole, and fluorquinolones) in Salmonella typhi is on the rise. ${ }^{46,47}$

Other concerns regarding the promotion of untested therapies for COVID-19 include fraud related to the growing

TABLE 1

Main side effects of Chloroquine and Hydroxychloroquine ${ }^{31-36}$

System

Cardiovascular

Gastrointestinal

Dermatologic

Musculoskeletal

Nervous

Psychiatric

Ocular

Metabolic
Chloroquine

QTc prolongation and cardiomyopathy

Nausea, vomiting, and abdominal pain

Pruritis

Myopathies and myasthenia-like syndromes

Seizures, tinnitus, and dystonia

Depression and psychosis

Maculopathy and macular degeneration, and retinopathy

Hypokalemia, hypercalcemia, and hypoglycemia
Hydroxychloroquine

QTc prolongation and cardiomyopathy Nausea, vomiting, and abdominal pain Pruritis

Sensorimotor disorders

Headache, dizziness, and tinnitus

Emotional lability

Blurred vision and retinopathy

Hypoglycemia 
TABLE 2

Drug interactions between $\mathrm{CQ} / \mathrm{HCQ}$ and antituberculous or antiretroviral therapies

\begin{tabular}{|c|c|}
\hline Medicine & Potential interaction with $\mathrm{CQ} / \mathrm{HCQ}$ \\
\hline Efavirenz & $\begin{array}{l}\text { Limited clinical data. May increase (inhibition of CYP2C8) or decrease } \\
\text { (induction of CYP3A4) exposure. Concurrent use may increase the risk } \\
\text { of QT interval prolongation. }\end{array}$ \\
\hline Lopinavir/ritonavir or atazanavir/ritonavir & $\begin{array}{l}\text { Limited clinical data. May increase exposure by inhibition of CYPs } 2 \mathrm{C} 8 \text {, } \\
\text { 3A4, and 2D6. Concurrent use may increase the risk of QTc interval } \\
\text { prolongation. }\end{array}$ \\
\hline Rifampicin & $\begin{array}{l}\text { Limited clinical data. Induces phase-I and phase-II enzymes and } \\
\text { transporters. Induction of CYP3A4 may decrease CQ/HCQ exposure. }\end{array}$ \\
\hline Levofloxacin and moxifloxacin & Concurrent use may increase the risk of QTc interval prolongation. \\
\hline Bedaquiline & Concurrent use may increase the risk of QTc interval prolongation. \\
\hline
\end{tabular}

market of substandard and falsified drugs ${ }^{48}$ and diversion of $\mathrm{CQ} / \mathrm{HCQ}$ from other chronic conditions for which they are medically indicated, in particular SLE and RA. ${ }^{49}$ Safety issues are especially concerning for Africa because of relatively weak monitoring systems for off-label drug use and adverse events; these systems are robust in countries with strong national insurance schemes or with adequate private sector medical insurance. In addition, the promotion of CQ/HCQ for COVID19 may lead to shortages and/or increased market prices of these medicines for malaria, SLE, and RA. One strategy to protect African countries from these threats is to leverage a collaborative network like the African Vaccine Regulatory Forum to coordinate cross-continental production, distribution chains, and post-marketing surveillance. Another model for quick, low-cost distribution of a COVID-19 drug or vaccine (once proven efficacious) would be to piggyback on platforms currently supported by the Global Fund, the U.S. President's Emergency Plan for AIDS Relief, and other organizations. African countries should also establish and strengthen prescription-monitoring schemes to ensure that off-label use of any drug(s) is appropriate and beneficial in this pandemic. For example, in South Africa, prescribers are required to inform the regulatory agency about off-label use of existing drugs in COVID-19 treatment. This process will help gather information on treatment outcomes pending results from clinical trials.

Importantly, patients at risk of COVID-19 complications are also those most at risk of drug-drug interactions and drugassociated toxicity. These include the following patients: 1) older than 60 years (estimated at $10-20 \%$ of the African pop-

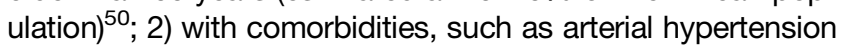
(30\% of African adults), ${ }^{51}$ diabetes ( $4 \%$ of African adults), ${ }^{52}$ chronic lung disease, malignancies, and immunosuppressive conditions; and 3) concurrently receiving medications with potential for drug interactions or additive toxicity. For these vulnerable populations, off-label CQ/HCQ use should be considered with the utmost care, ideally following monitored research protocols in hospital and outpatient settings.

In conclusion, there is currently no evidence that $\mathrm{CQ}$ or $\mathrm{HCQ}$, two low-cost drugs for which we have extensive experience for treatment of malaria and rheumatic disorders, has beneficial effects on the clinical course of COVID-19 patients. There are more than 80 ongoing trials of $C Q$ or $\mathrm{HCQ}$, used alone or in combination with a variety of other drugs registered on ClinicalTrials.gov. The results of these studies, including Solidarity and its companion trials (Discovery and Recovery) as well as COPCOV are eagerly awaited. Meanwhile, the offlabel use of CQ and HCQ to prevent or treat COVID-19 in Africa and elsewhere must be viewed with greatest caution, considering potential serious toxicities and benefit versus risk. If the effectiveness of these and other drugs is established in global trials, therapeutics for COVID-19 will require further operational evaluation in Africa.

Received April 14, 2020. Accepted for publication April 16, 2020.

Published online April 22, 2020.

Acknowledgments: We thank David Sullivan and Clive Schiff, Johns Hopkins Bloomberg School of Public Health, Baltimore, MD, for their critical reading of our manuscript. Publication charges for this article were waived due to the ongoing pandemic of COVID-19.

Disclosure: Nachega is an infectious disease internist and epidemiologist supported by U.S. National Institutes of Health (NIH)/National Institutes of Allergy and Infectious Diseases (NIAID) grant number 5U01Al069521 (Stellenbosch University Clinical Trial Unit (CTU) of AIDS Clinical Trial Group [ACTG]) as well as $\mathrm{NIH} /$ Fogarty International Center (FIC) grant numbers 1R25TW011217-01 (African Association for Health Professions Education and Research) and 1D43TW010937$01 \mathrm{~A} 1$ (the University of Pittsburgh HIV-Comorbidities Research Training Program in South Africa). He serves on the scientific program committee of the American Society of Tropical Medicine and Hygiene (ASTMH) and is a senior fellow alumni of the European Developing Countries Clinical Trial Partnership (EDCTP). Muyembe-Tamfum has been on the front lines of Ebola research since 1970s, identifying nosocomial and burial transmission as two of the major causes of disease transmission, contributing to vaccine research, developing antisera therapy, and training a new generation of disease responders and Congolese laboratory. He is now leading the COVID-19 Task Force Response in the Democratic Republic of the Congo. Sir Zumla is a co-PI of the Pan-African Network on Emerging and Re-Emerging Infections (PANDORA-ID-NET-https://www.pandora-id.net/) funded by the EDCTP, the EU Horizon 2020 Framework Program for Research and Innovation. Sir Zumla is in receipt of a National Institutes of Health Research senior investigator award. Seydi is an infectious diseases and tropical medicine expert and member of the COVID-19 Task Force Response in Senegal. Suleman is a Public Health Pharmacist supported by a NIH/Fogarty International Center (FIC) grant number 1R25TW011217-01 (African Association for Health Professions Education and Research). Dr. Sam-Agudu is a Pediatric Infectious Diseases clinician-scientist supported by the $\mathrm{NIH} / \mathrm{National}$ Institute of Child Health and Human Development (NICHD) grant R01HD089866, and by an NIH/FIC award under the Adolescent HIV Prevention and Treatment Implementation Science Alliance (AHISA), for the Central and West Africa Implementation Science Alliance (CAWISA). Prisca Olabisi Adejumo is a professor of Medical Surgical Nursing, a nurse educator supported by $\mathrm{NIH} /$ Fogarty International Center (FIC) grant number 1R25TW011217-01 (African Association for Health Professions Education and Research). All authors have an interest in emerging and reemerging pathogens and declare no conflicts of interest.

Authors' addresses: Pascale M. Abena, Infectious Diseases Outpatient Clinic, Douala, Cameroon, E-mail: abenamessomo@yahoo.fr. 
Eric H. Decloedt, Division of Clinical Pharmacology, Department of Medicine, Stellenbosch University, Cape Town, South Africa, E-mail: ericdecloedt@sun.ac.za. Emmanuel Bottieau, Department of Clinical Sciences, Institute of Tropical Medicine, Antwerp, Belgium, E-mail: ebottieau@itg.be. Fatima Suleman, Discipline of Pharmaceutical Sciences, University of Kwazulu-Natal, Durban, South Africa, E-mail: sulemanf@ukzn.ac.za. Nadia A. Sam-Agudu, Institute of Human Virology Nigeria, International Research Center of ExcellenceAbuja, Nigeria, Division of Epidemiology and Prevention, Institute of Human Virology, Baltimore, MD, and Department of Paediatrics, University of Cape Coast School of Medical Sciences, Cape Coast, Ghana, E-mail: nsamagudu@ihvnigeria.org. Jean-Jacques Muyembe TamFum, Department of Virology, National Instute of Bio-Medical Research (INRB), Kinshasa, Democratic Republic of the Congo, Universite de Kinshasa, Microbiologie et Virologie Medicale, Kinshasa, Democratic Republic of the Congo, E-mail: jjmuyembet@gmail.com. Moussa Seydi, Service de Maladies Infectieuses et Tropicales, Centre Hospitalo-Universitaire de Fann, Université Cheik Anta-Diop, Dakar, Sénégal, E-mail: seydi.moussa@gmail.com. Serge P. Eholie, Programme PAC-Cl, N/A, Abidjan, Côte d'Ivoire, E-mail: sergeholie@yahoo.fr. Edward J. Mills, School of Public Health, University of Kigali, Kigali, Rwanda, E-mail: emills@mteksciences.com. Oscar Kallay, Department of Ophthalmology, Erasmus University Clinics, Brussels, Belgium, E-mail: oscar_ kallay@yahoo.fr. Alimuddin ZumlaFRCP, Department of Infection, Division of Infection and Immunity, Centre for Clinical Microbiology, University College London, London, United Kingdom, and National Institute for Health Research Biomedical Research Centre, University College London Hospitals, London, United Kingdom, E-mail: a.zumla@ucl.ac.uk. Jean B Nachega, Center for Infectious Diseases, at Stellenbosch University, Cape Town, South Africa, Department of International Health and Epidemiology, Johns Hopkins Bloomberg School of Public Health, Baltimore, MD, and University of Pittsburgh Graduate School of Public Health and Center for Global Health, Pittsburgh, PA, E-mail: jbn16@pitt.edu.

This is an open-access article distributed under the terms of the Creative Commons Attribution (CC-BY) License, which permits unrestricted use, distribution, and reproduction in any medium, provided the original author and source are credited.

\section{REFERENCES}

1. World Health Organization, 2020. Coronavirus Disease 2019 (COVID-19) Situation Report - 86. Available at: https://www. who.int/emergencies/diseases/novel-coronavirus-2019/ situation-reports. Accessed April 16, 2020.

2. Kolifarhood K, Aghaali M, Saadati HM, Taherpour N, Rahimi S, Izadi N, Nazari SSH, 2020. Epidemiological and clinical aspects of COVID-19; anNarrative review. Arch Acad Emerg Med 8: e41.

3. Zhou F et al., 2020. Clinical course and risk factors for mortality of adult inpatients with COVID-19 in Wuhan, China: a retrospective cohort study. Lancet 395: 1054.

4. Maguire BJ, Guérin PJ, 2020. A living systematic review protocol for covid-19 clinical trial registrations. Wellcome Open Res 5: 60.

5. Keshtkar-Jahromi M, Bavari S, 2020. A call for randomized controlled trials to test the efficacy of chloroquine and hydroxychloroquine as therapeutics against novel coronavirus disease (COVID-19). Am J Trop Med Hyg 102: 932-933.

6. Touret F, de Lamballerie X, 2020. Of chloroquine and COVID-19. Antiviral Res 177: 104762.

7. Rainsford KD, Parke AL, Clifford-Rashotte M, Kean WF, 2015. Therapy and pharmacological properties of hydroxychloroquine and chloroquine in treatment of systemic lupus erythematosus, rheumatoid arthritis and related diseases. Inflammopharmacology 23: 231-269.

8. World Health Organization, 2020. Model List of Essential Medicines, 2019. Available at: https://apps.who.int/iris/bitstream/ handle/10665/325771/WHO-MVP-EMP-IAU-2019.06-eng.pdf? ua=1. Accessed April 14, 2020.

9. Borba $\mathrm{M}$ et al., Chloroquine diphosphate in two different dosages as adjunctive therapy of hospitalized patients with severe respiratory syndrome in the context of coronavirus (SARS-CoV-2) infection: preliminary safety results of a randomized, doubleblinded, phase Ilb clinical trial (CloroCovid-19 Study). Medrxiv [ePub ahead of print]. Available at: https://www.medrxiv.org/ content/10.1101/2020.04.07.20056424v2. Accessed on April 21, 2020.

10. Gbinigie K, Frie K, 2020. Should chloroquine and hydroxychloroquine be used to treat COVID-19? A rapid review. BJGP Open bjgpopen20X101069. Available at: https://doi.org/ 10.3399/bjgpopen20X101069.

11. Jensen M, Mehlhorn H, 2009. Seventy-five years of Resochin in the fight against malaria. Parasitol Res 105: 609-627.

12. WHO, 2015. Guidelines for the Treatment of Malaria, 3rd edition. Geneva, Switzerland: World Health Organization. Available at: http://www.who.int/malaria/publications/atoz/ 9789241549127/en/. Accessed on April 21, 2020.

13. Shippey EA, Wagler VD, Collamer AN, 2018. Hydroxychloroquine: an old drug with new relevance. Cleve Clin J Med 85: 459-467.

14. Costedoat-Chalumeau N, Dunogué B, Leroux G, Morel N, Jallouli M, Le Guern V, Piette JC, Brézin AP, Melles RB, Marmor MF, 2015. A critical review of the effects of hydroxychloroquine and chloroquine on the eye. Clin Rev Allergy Immunol 49: 317-326.

15. Cortegiani A, Ingoglia G, Ippolito M, Giarratano A, Einav S, 2020. A systematic review on the efficacy and safety of chloroquine for the treatment of COVID-19. J Crit Care S0883-9441: 30390-30397.

16. Roques $P$ et al., 2018. Paradoxical effect of chloroquine treatment in enhancing chikungunya virus infection. Viruses 10: E268.

17. Mauthe $\mathrm{M}$ et al., 2018. Chloroquine inhibits autophagic flux by decreasing autophagosome-lysosome fusion. Autophagy 14: $1435-1455$.

18. Savarino A, di Trani L, Donatelli I, Cauda R, Cassone A, 2006. New insights into the antiviral effects of chloroquine. Lancet Infect Dis 6: 67-69.

19. Zhang H, Penninger JM, Li Y, Zhong N, Slutsky AS, 2020. Angiotensin-converting enzyme 2 (ACE2) as a SARS-CoV-2 receptor: molecular mechanisms and potential therapeutic target. Intensive Care Med 46: 586-590.

20. Landewé RB, Miltenburg AM, Verdonk MJ, Verweij CL, Breedveld FC, Daha MR, Dijkmans BA, 1995. Chloroquine inhibits T cell proliferation by interfering with IL-2 production and responsiveness. Clin Exp Immunol 102: 144-151.

21. Sahraei Z, Shabani M, Shokouhi S, Saffaei A, 2020. Aminoquinolines against coronavirus disease 2019 (COVID-19): chloroquine or hydroxychloroquine. Int $J$ Antimicrob Agents [ePub ahead of print]. Available at: https://doi.org/10.1016/ j.ijantimicag.2020.105945. Accessed on April 21, 2020.

22. Gao J, Tian Z, Yang X, 2020. Breakthrough: chloroquine phosphate has shown apparent efficacy in treatment of COVID-19 associated pneumonia in clinical studies. Biosci Trends 14: 72-73.

23. Chen J et al., 2020. Preprint: a pilot study of hydroxychloroquine in treatment of patients with common coronavirus disease-19 (COVID-19). J Zhejiang Univ [ePub ahead of print]. Available at: https://doi.org/10.3785/j.issn.1008-9292.2020.03.03. Accessed April 21, 2020.

24. Chen Z, Hu J, Zhang Z, Jiang S, Han S, Yan D, Zhuang R, Hu B, Zhang Z, 2020. Preprint: efficacy of hydroxychloroquine in patients with COVID-19: results of a randomized clinical trial. Medrxiv. Available at: https://www.medrxiv.org/content/10.1101/ 2020.03.22.20040758v2. Accessed April 3, 2020.

25. Gautret $P$ et al., 2020. Hydroxychloroquine and azithromycin as a treatment of COVID-19: results of an open-label nonrandomized clinical trial. Int $J$ Antimicrob Agents [ePub ahead of print]. Available at: https://doi.org/10.1016/j.ijantimicag. 2020.105949. Accessed April 21, 2020.

26. Molina JM, Delaugerre C, Le Goff J, Mela-Lima B, Ponscarme D, Goldwirt L, de Castro N, 2020. Journal pre-proof: no evidence of rapid antiviral clearance or clinical benefit with the combination of hydroxychloroquine and azithromycin in patients with severe COVID-19 infection. Med Mal Infect [ePub ahead of print]. Available at: https://doi.org/10.1016/j.medmal.2020.03.006. Accessed April 21, 2020.

27. The WHO SOLIDARITY Trial: ClinicalTrials.gov (NCT04280705), 2020. Adaptive COVID-19 treatment trial (ACTT). Available at: https://clinicaltrials.gov/ct2/show/NCT04280705? cond $=$ NCT04280705\&draw $=2 \&$ rank $=1$. Accessed March 30, 2020. 
28. University of Oxford, 2020. Chloroquine/hydroxychloroquine prevention of coronavirus disease (COVID-19) in the healthcare Setting (COPCOV). Available at: https://www.clinicaltrials.gov/ ct2/show/NCT04303507. Accessed April 16, 2020.

29. Politi D, 2020. Nigeria Reports Chloroquine Poisonings as Trump Keeps Pushing Drug against Coronavirus. Available at: https:// slate.com/news-and-politics/2020/03/nigeria-chloroquinepoisonings-trump-pushing-drug-coronavirus.html. Accessed April 12, 2020.

30. US Food and Drug Administration, 2020. Aralen (Chloroquine Phosphate, USP) Package Insert. Available at: https://www. accessdata.fda.gov/drugsatfda_docs/label/2017/006002s044lbl. pdf. Accessed April 14, 2020.

31. Chatre C, Roubille F, Vernhet H, Jorgensen C, Pers YM, 2018. Cardiac complications attributed to chloroquine and hydroxychloroquine: a systematic review of the literature. Drug Saf 41: 919-931.

32. Arentz M, Yim E, Klaff L, Lokhandwala S, Riedo FX, Chong M, Lee $M, 2020$. Characteristics and outcomes of 21 critically III patients with COVID-19 in Washington state. JAMA [ePub ahead of print]. Available at: https://doi.org/10.1001/jama.2020.4326.

33. Unubol M, Ayhan M, Guney E, 2011. Hypoglycemia induced by hydroxychloroquine in a patient treated for rheumatoid arthritis. J Clin Rheumatol 17: 46-47.

34. Winter EM, Schrander-van der Meer A, Eustatia-Rutten C, Janssen M, 2011. Hydroxychloroquine as a glucose lowering drug. BMJ Case Rep bcr0620114393.

35. Taylor WR, White NJ, 2004. Antimalarial drug toxicity: a review. Drug Saf 27: 25-61.

36. Ray WA, Murray KT, Hall K, Arbogast PG, Stein CM, 2012. Azithromycin and the risk of cardiovascular death. N Engl J Med 366: 1881-1890.

37. Ducharme J, Farinotti R, 1996. Clinical pharmacokinetics and metabolism of chloroquine. Focus on recent advancements. Clin Pharmacokinet 31: 257-274.

38. Projean D, Baune B, Farinotti R, Flinois J-P, Beaune $P$, Taburet A-M, Ducharme J, 2003. In vitro metabolism of chloroquine: identification of CYP2C8, CYP3A4, and CYP2D6 as the main isoforms catalyzing $\mathrm{N}$-desethylchloroquine formation. Drug Metab Dispos 31: 748-754

39. Kim K-A, Park J-Y, Lee J-S, Lim S, 2003. Cytochrome P450 2C8 and CYP3A4/5 are involved in chloroquine metabolism in human liver microsomes. Arch Pharm Res 26: 631-637.

40. Efavirenz CQ, HCQ, 2020. Drug Interactions, 2020. Micromedex Solutions. Ann Arbor, MI: Truven Health Analytics, Inc.
Available at: http://www.micromedexsolutions.com. Accessed April 13, 2020.

41. University of Liverpool, 2020. COVID-19 Drug-Drug Interactions Website. Available at: https://www.covid19-druginteractions. org/. Accessed April 21, 2020.

42. Williamson B, Dooley KE, Zhang Y, Back DJ, Owen A, 2013. Induction of Influx and efflux transporters and cytochrome P450 3A4 in primary human hepatocytes by Rifampin, Rifabutin, and Rifapentine. Antimicrob Agents Chemother 57: 6366-6369.

43. Desta Z, Soukhova NV, Flockhart DA, 2001. Inhibition of cytochrome P450 (CYP450) isoforms by isoniazid: potent inhibition of CYP2C19 and CYP3A. Antimicrob Agents Chemother 45: 382-392.

44. Drug Interactions. Micromedex Solution, 2020. Ann Arbor, Ml: Truven Health Analytics, Inc. Available at: http://www. micromedexsolutions.com. Accessed April 13, 2020.

45. Conrad MD, Rosenthal PJ, 2019. Antimalarial drug resistance in Africa: the calm before the storm? Lancet Infect Dis 19: e338-e351.

46. Lunguya O et al., 2012. Salmonella typhi in the Democratic Republic of the Congo: fluoroquinolone decreased susceptibility on the rise. PLoS Negl Trop Dis 6: e1921.

47. Browne AJ et al., 2020. Drug-resistant enteric fever worldwide, 1990 to 2018: a systematic review and meta-analysis. BMC Med 18: 1.

48. Newton PN, Bond KC, 2019. Oxford Statement signatories. Global access to quality-assured medical products: the Oxford Statement and call to action. Lancet Glob Health 7: e1609-e1611.

49. Decloedt E, Reuter H, Allwoood B, Parker A, Koegelenberg CFN, Blockman M, Taljaard J, 2020. Benefit versus risk when using chloroquine in patients with severe COVID-19 disease. S Afr Med J. Available at: http://www.samj.org.za/index.php/samj/ article/view/12903. Accessed April 21, 2020.

50. Anonymous, 2019. Population Pyramids of the World from 1950 to 2100. Available at: https://www.populationpyramid.net/ africa/2019/. Accessed April 21, 2020.

51. Ataklte F, Erqou S, Kaptoge S, Taye B, Echouffo-Tcheugui JB, Kengne AP, 2015. Burden of undiagnosed hypertension in subSaharan Africa: a systematic review and meta-analysis. Hypertension 65: 291-298.

52. International Diabetes Federation (IDF), 2019. IDF Diabetes Atlas 2019. Available at: https://www.diabetesatlas.org/en/\&tnqh 34/. Accessed April 21, 2020. 